\title{
MEKANISASI PENCETAK KUE KACANG
}

\author{
${ }^{1}$ Yang Fitri Arriyani, ${ }^{2}$ Husman, ${ }^{3}$ Rio Ardiansyah, ${ }^{4}$ Vidian Suryani \\ 1,2,3,4 Jurusan Teknik Mesin - Politeknik Manufaktur Negeri Bangka Belitung \\ Jl. Timah Raya, Air Kantung, Sungailiat - Indonesia \\ Telp. 0717 93586, Yangfia74@gmail.com
}

\begin{abstract}
Peanut cake is one of the typical Indonesian pastries which includes the most popular cakes by Indonesian people including the people of the Province of Bangka Belitung Islands. The process of processing peanut cakes through several stages, namely the processing of peanuts, the printing of bean cake dough. The current method of printing peanut cakes is still manually using one by one as a tool to print the bean cake. The purpose of this study is to design and make a bean cake printing tool that is capable of printing 20 bean cakes in one process. The stages in making this bean cake printing device start from problem identification, planning, designing, tool making, assembling, and testing. Based on the results of the trials that have been carried out, the tool is capable of printing 20 prints in a single process and the dough is not attached to the mold.
\end{abstract}

Keywords: peanut cake, manual, cake maker

\begin{abstract}
Abstrak
Kue kacang adalah salah satu kue kering khas Indonesia yang termasuk kue paling digemari oleh masyarakat Indonesia termasuk masyarakat Provinsi Kepulauan Bangka Belitung. Proses pengolahan kue kacang melalui beberapa tahapan, yaitu pengolahan kacang, pemipihan adonan dan pencetakan adonan kue kacang yang telah dipipihkan. Metode pencetakan kue kacang yang dilakukan saat ini masih secara manual yaitu dengan mencetak satu persatu kue kacang tersebut. Hal ini mengakibatkan kapasitas produksi yang dapat dihasilkan sedikit dan dibutuhkan waktu yang lama untuk proses pencetakan. Tujuan dari penelitian ini adalah merancang dan membuat pencetak kue kacang yang mampumencetak 20 kuekacangdalamsekali proses secara mekanis. Tahapan-tahapan dalam pembuatan alat pencetak kue kacang ini dimulai dari identifikasi masalah, perencanaan, perancangan, pembuatan alat, perakitan, dan uji coba. Berdasarkan hasil uji coba yang telah dilakukan, alat mampu mencetak 20 kue kacang dalam satu kali proses dan adonan tidak melekat pada cetakan.
\end{abstract}

Kata kunci: kue kacang, manual, pencetak kue

\section{PENDAHULUAN}

Industri kue kering merupakan industri makanan yang memanfaatkan tepung terigu sebagai bahan baku utama dalam proses produksinya. Produk kue kering biasanya disajikan dalam bentuk yang spesifik sebagai ciri jenis makanan yang bersangkutan, maupun untuk mendapatkan estetika yang menarik dengan bentuk yang kreatif dan berkembang [1]. Kue kacang merupakan salah satu kue kering yang sering ditemui saat perayaan hari-hari besar keagamaan. Makanan ini banyak digemari karena rasanya yang enak, gurih dan manis. Kue kacang terbuat dari adonan tepung terigu, telur, gula halus, garam, mentega, minyak sayur dan kacang tanah.

Proses pembuatan kue kacang diawali dengan menyangrai kacang tanah terlebih dahulu. Setelah disangrai, kacang dipisahkan dari kulit arinya kemudian ditumbuk atau dihaluskan. Langkah selanjutnya adalah mencampurkan kacang yang telah ditumbuk halus ke adonan tepung terigu, garam, gula, juga margarine atau minyak sayur. Aduk semua adonan tersebut sampai merata dan kalis. Setelah kalis, selanjutnya dipipihkan dengan kayu silinder untuk mendapatkan hasil adonan yang tebalnya merata, kurang lebih 5 hingga $7 \mathrm{~mm}$. Setelah itu, adonan siap untuk dicetak sesuai dengan cetakan dengan bentuk yang diinginkan. Pada bagian atas kue yang telah dicetak, diolesi kuning telur sebagai toping agar tampilan kue menjadi menarik. Kemudian dipanggang hingga matang dan didinginkan agar tidak hancur pada saat akan dikemas ke dalam wadah. Gambar 1 menunjukkan tahapan proses pembuatan kue kacang. 


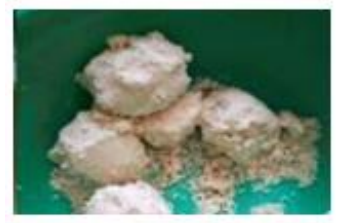

(a)

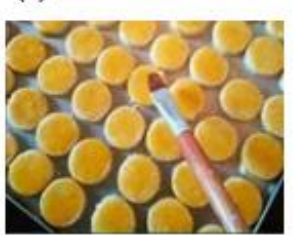

(d)

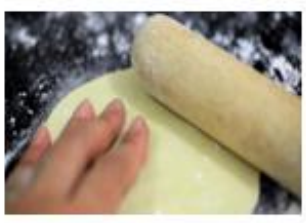

(b)

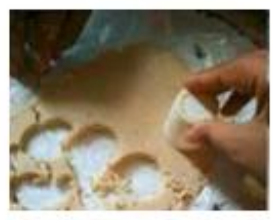

(c)

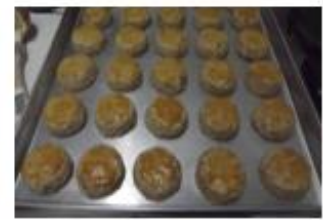

(e)

Gambar 1. Tahapan Proses Pembuatan Kue Kacang

(a). Proses pencampuran adonan, (b). Proses pemipihanadonan, (c). Pencetakan kue, (d). Pengolesan toping, (e) Proses pemanggangan

Proses pembuatan kue kacang yang dilakukan oleh pembuat kue saat ini masih melakukan proses pencetakan kue satu per satu dari adonan yang telah dipipihkan. Hal ini menimbulkan waktu pembuatan yang dibutuhkan cukup lama dan produksi kue yang dihasilkan hanya dalam jumlah kecil. Untuk itu dirancang dan dibangun alat yang dapat mempercepat proses pencetakan kue sehingga dapat meningkatkan hasil produksi kue kacang dengan waktu yang lebih singkat. Hasil kue kacang dari alat pencetak ini berbentuk bundar berdiameter kurang lebih $30 \mathrm{~mm}$ dan dapat memotong adonan pipih dengan ketebalan hingga $7 \mathrm{~mm}$. Dalam sekali proses pencetakan alat ini mampu menghasilkan 20 kue kacang sekaligus.

\section{METODE PENELITIAN}

Metode penelitian merupakan suatu cara yang digunakan dalam mengumpulkan data penelitian dan membandingkan dengan standar ukuran yang telah ditentukan[2]. Metode Penelitian yang dilakukan pada alat pencetak kue kacang ini adalah dengan mengikuti diagram alir yang ditunjukkan pada gambar 2.

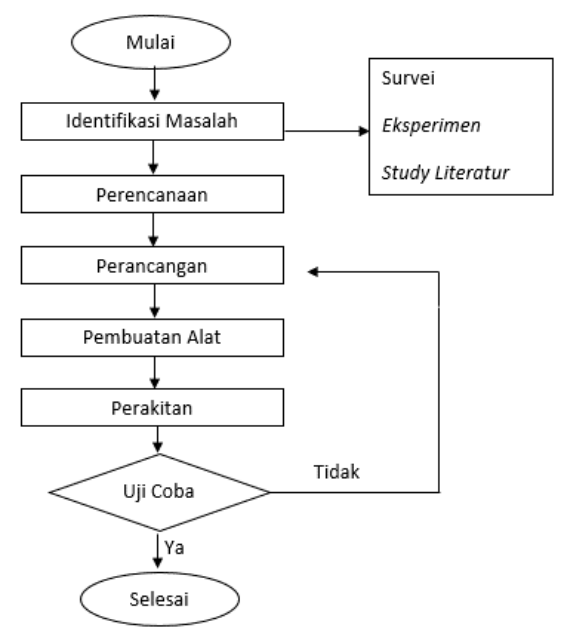

Gambar 2 Diagram Alir Tahapan Penelitian Alat Pencetak Kue Kacang

Dalam mengidentifikasi masalah dilakukan beberapa cara, yaitu survey, eksperimen, dan studi literatur. Survey dilakukan di industri rumahan dengan melakukan wawancara ke seorang pembuat kue kacang. Informasi yang diperoleh adalah tentang keluhan dan permasalahan-permasalahan tentang proses pencetakan kue. Selain survey juga dilakukan eksperimen yang menunjukkan bahwa dalam sekali 
cetak, waktu yang diperlukan untuk mulai mencetak hingga menempatkan kue kacang di loyang pemanggangan adalah 2 detik.

\section{HASIL DAN PEMBAHASAN}

Rancangan alat pencetak kue kacang memiliki daftar tuntutan seperti yang ditunjukkan pada tabel 3.1. Daftar tuntutan ini merupakan target yang harus dicapai dan menjadi syarat-syarat yang harus dipenuhi untuk alat pencetak kue kacang yang dirancang.

Tabel 1 Daftar Tuntutan Alat Pencetak Kue Kacang

\begin{tabular}{|c|c|c|}
\hline No & Daftar Tuntutan & Deskripsi \\
\hline 1 & Tuntutan utama & \\
\hline 1.1 & Kapasitas & 20 kue kacang dalam sekali proses \\
\hline 1.2 & Pengeluaran output & berbentuk bundar $\varnothing 30 \times 7 \mathrm{~mm}$ \\
\hline 2 & Tuntutan kedua & \\
\hline 2.1 & Konstruksi alat & $\begin{array}{l}\text { Kuat dan kokoh sehingga tidak cepat } \\
\text { rusak }\end{array}$ \\
\hline 2.2 & Higienis & $\begin{array}{l}\text { Material yang digunakan higienis } \\
\text { (stainless) untuk makanan }\end{array}$ \\
\hline 3 & Keinginan & \\
\hline 3.1 & Aman dan mudah dioperasikan & Tidak mempersulit pengguna pada saat \\
\hline 3.2 & Rangka sederhana & pengoperasian \\
\hline 3.3 & Perawatan mudah & Tidak membutuhkan alat khusus hanya \\
\hline 3.4 & Harga alat ekonomis & $\begin{array}{l}\text { membutuhkan } 2 \text { media air dan kain, alat } \\
\text { dan bahan mudah didapat dan harga } \\
\text { terjangkau }\end{array}$ \\
\hline
\end{tabular}

Ada 3 (tiga) alternatif rancangan yang dibuat dari daftar tuntutan di atas. Ketiga alternatif tersebut kemudian dievaluasi untuk mendapatkan alternatif rancangan yang terbaik untuk dibuat dan diproses pemesinan. Ketiga alternatif rancangan yang telah dibuat dan dievaluasi ditunjukkan pada gambar di bawah ini.
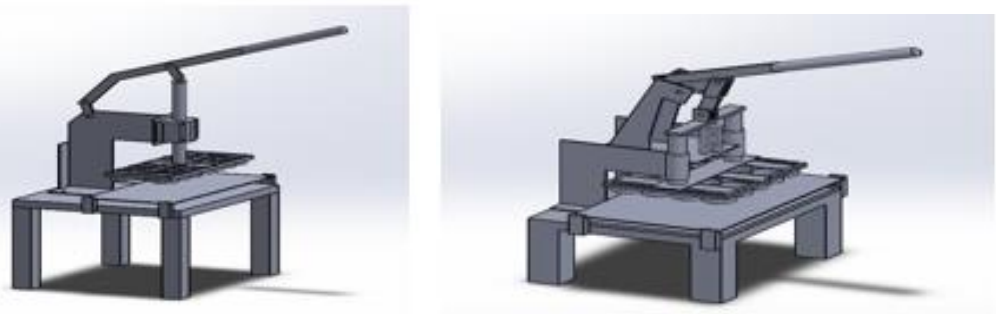

Gambar 3. Alternatif rancangan 1 dan Alternatif rancangan 2

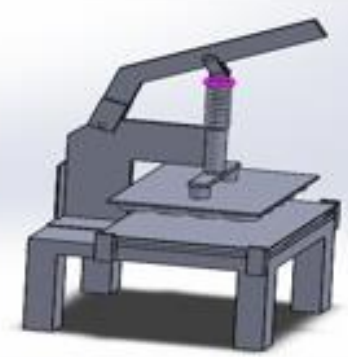

Gambar 4. Alternatif Rancangan 3

Dari ketiga alternatif rancangan tersebut hasil evaluasi menunjukkan bahwa alternatif rancangan 1 memiliki banyak kelebihan dan keuntungan dibandingkan dengan kedua alternatif lainnya. Nilai komulatif dari kriteria-kriteria yang dijadikan indikator alat pencetak yang terbaik adalah sebesar 30. 
Sehingga dapat dilakukan pengembangan dari alternatif rancangan 1 serta dilakukan perhitungan terhadap beban yang terjadi pada bagian-bagian yang utama dari alat tersebut.

Tabel 2 Penilaian Alternatif Rancangan

\begin{tabular}{llcccc}
\hline & \multicolumn{1}{c}{ Kriteria } & Nilai & \multicolumn{2}{c}{ Alternatif Konsep } \\
\cline { 3 - 5 } & & max & ALT.1 & ALT.2 & ALT.3 \\
\hline 1 & Penggunaan tenaga & $\mathbf{4}$ & 3 & 2 & 2 \\
2 & Hasil cetakan yang baik & 4 & 3 & 2 & 1 \\
3 & Kuat dan tahan lama & 4 & 4 & 4 & 4 \\
4 & Komponen yang sedikit & 4 & 4 & 2 & 3 \\
5 & Kemampuan mencetak adonan kue & 4 & 4 & 4 & 1 \\
6 & Harga yang murah & $\mathbf{4}$ & 4 & 3 & 3 \\
7 & Pengoperasian mudah & $\mathbf{4}$ & 4 & 4 & 4 \\
8 & Pemasangan mudah & $\mathbf{4}$ & 4 & 3 & 4 \\
\hline & Jumlah & $\mathbf{3 2}$ & $\mathbf{3 0}$ & $\mathbf{2 4}$ & $\mathbf{2 2}$
\end{tabular}

\subsection{Analisa Perhitungan}

Perencanaan alat pencetak kue kacang dilanjutkan dengan menghitung kekuatan tuas penekan dan poros pemegang cetakan. Dari diagram benda bebas (DBB) alat cetak, terlihat bahwa akan terjadi tegangan bengkok pada tuas penekan pada saat proses pencetakan kue. Perhitungan tegangan bengkok menggunakan rumus seperti berikut ini.

- Menghitung momen bengkok:

$$
M b=F . L
$$

- Tegangan bengkok yang diijinkan

$$
\sigma i=\frac{M a}{W}
$$

- Tahanan Bengkok untuk profil lingkaran

$$
W=\frac{\pi}{32} \cdot d^{3}
$$

Hasil perhitungan menunjukkan bahwa dengan besar $F=50 \mathrm{~N}$ dan jarak $\mathrm{L}=374,4 \mathrm{~mm}$ maka poros yang harus digunakan untuk tuas tekan minimal berdiameter $14,15 \mathrm{~mm}$ atau dibulatkan menjadi $15 \mathrm{~mm}$ dengan material stainless steel.Hasil proses pemesinan dan perakitan dari alternatif rancangan yang telah dikembangkan dapat dilihat pada gambar 5 .

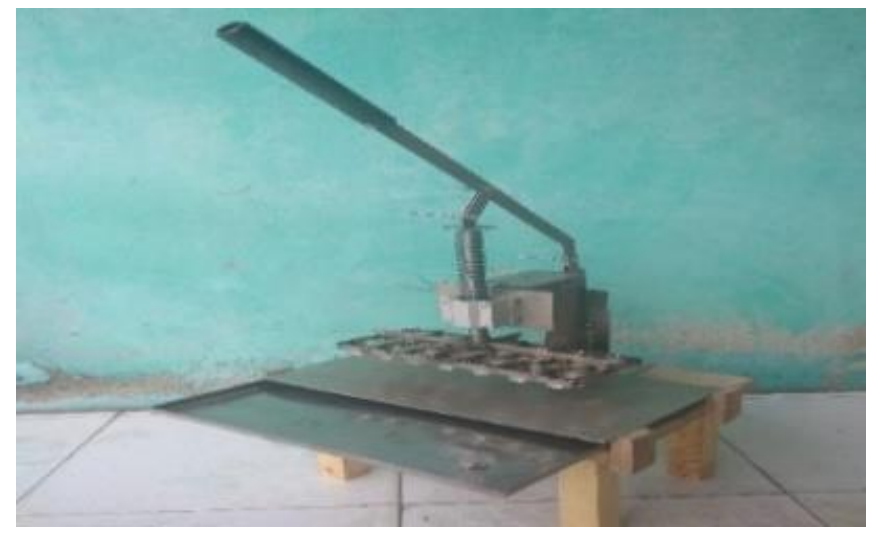

Gambar 5 Alat Pencetak Kue Kacang 


\subsection{Uji Coba Alat}

Uji coba alat dilakukan sebanyak 3 kali dengan hasil uji coba sebagai berikut:

Tabel 3. Hasil Uji Coba Alat

\begin{tabular}{ccl}
\hline Uji Coba Ke & $\begin{array}{c}\text { Jumlah } \\
\text { Cetakan }\end{array}$ & \multicolumn{1}{c}{ Hasil Cetakan } \\
\hline $\begin{array}{c}\text { Tidak menggunakan } \\
\text { minyak sayur sebagai } \\
\text { pelumas }\end{array}$ & 20 & $\begin{array}{l}\text { Adonan tercetak semua namun hanya sebagian } \\
\text { yang tercetak dan langsung terpisah dari } \\
\text { cetakan. Sebagian kue hasil cetakan lengket } \\
\text { dicetakan. }\end{array}$ \\
\hline $\begin{array}{c}\text { Menggunakan minyak } \\
\text { sayur sebagai pelumas }\end{array}$ & 20 & $\begin{array}{l}\text { Adonan tercetak semua. Hasil cetakan yang } \\
\text { terpisahtidak lengket pada cetakan. }\end{array}$ \\
\hline $\begin{array}{c}\text { Menggunakan minyak } \\
\text { sayur sebagai pelumas }\end{array}$ & 20 & $\begin{array}{l}\text { Adonan tercetak semua. Hasil cetakan yang } \\
\text { terpisah tidak lengket pada cetakan. }\end{array}$ \\
\hline
\end{tabular}

\section{SIMPULAN}

- $\quad$ Alat pencetak kue kacang dapat digunakan untuk mencetak 20 kue kacang sekaligus dalam sekali tekan, sehingga waktu pencetakan yang lebih cepat sehingga hasil produksi kue kacang dapat ditingkatkan.

- $\quad$ Bentuk kue hasil cetakan bundar dengan diameter kurang lebih $30 \mathrm{~mm}$ dan tebal kurang lebih 7 $\mathrm{mm}$ dan setelah diuji coba tidak mengalami kerusakan akibat proses pencetakan. Minyak sayur sebagai pelumas dapat juga diganti dengan tepung terigu untuk menghindari lengketnya kue yang dicetak pada cetakannya.

- Kerataan permukaan dari 20 buah cetakan harus tercapai agar hasil cetakan sebanyak 20 buah dapat terputus semua dari adonan yang telah dipipihkan.

\section{DAFTAR PUSTAKA}

[1]. Dwi Handayani, Anindya Ardiayasari dan Rico Vendamawan, "Penerapan AlatPencetak Kue "Unthuk Yuyu" Secara Kontinyu untuk Meningkatkan Kapasitas Produksi”, Jurnal Metana, Vol. 12(2), pp. 59-62, 2016

[2]. Suharsimi Arikunto, Prosedur penelitian suatu pendekatan praktik, Jakarta: Rineka cipta, Hal 126, 2012.

[3]. Pratama, Rancang Bangun Alat Pembelah Pinang Semi Mekanik, Skripsi Universitas Andalas, Padang, 2014.

[4]. Kamsiah, Lorika Zika, Hendias, Rancang Bangun Alat Pencetak Kue Bipang Kacang, Laporan Proyek Akhir, Sungailiat: Politeknik Manufaktur Negeri Bangka Belitung, 2017.

[5]. Ayi Ruswandi, Metode Perancangan 1, Bandung: Polman Bandung, 2004. 